\title{
SeVERE Cholestatic SyndRome Secondary to GRAVES' DiseASE
}

\author{
Rodrigo Piltcher da Silva ${ }^{1}$, Sabino Junior ${ }^{1}$, Matheus Bernardon Morillos ${ }^{1}$, \\ Isabella Roque Miclos ${ }^{2,3}$, Letícia Schwerz Weinert ${ }^{4,5}$, \\ Rogério Torres Marques 6
}

\begin{abstract}
This paper reports a case of severe cholestasis as an atypical manifestation of Graves' disease. It discusses the pathophysiology, the diagnosis and the investigation of this complication of hyperthyroidism as well as the impact of this finding on the therapeutic options for managing the disease.
\end{abstract}

Keywords: Graves' disease; hyperthyroidism; cholestasis

Thyrotoxicosis is the clinical manifestation of an excessive release of thyroid hormones, associated or not with glandular hyperfunction. The main etiologies are Graves' disease (GD), toxic adenoma, toxic multinodular goiter, subacute thyroiditis, and thyrotoxicosis factitia ${ }^{1}$. GD is the most common form of hyperthyroidism, accounting for $60 \%$ to $80 \%$ of cases, with a women-to-men ratio of 5 to 10 and a higher incidence among those aged 40 to 60 years ${ }^{1}$.

Initially described by Robert Graves in 1835, GD is an autoimmune disease which presents with some typical symptoms, such as weight loss, anxiety, tremors, ophthalmopathy and diffuse goiter ${ }^{2,3}$. However, in the past few decades, several atypical clinical manifestations have been reported, such as anemia, thrombocytopenia, acute myocardial infarction, and jaundice ${ }^{2}$. This report discusses the case of a patient with GD manifested as severe jaundice.

\section{CASE REPORT}

A 46-year-old male patient sought emergency care complaining of inappetence, dyspepsia, and weight loss of 16 kilograms over the course of 4 months, followed by abdominal discomfort and sudden onset of jaundice. He reportedly did not smoke, drink alcohol or use illicit drugs. He also reported having experienced symptoms of proptosis, fatigue and eventual palpitation during the previous year, which compromised his daily activities. Thus, he was referred for hospital admission because of suspected periampullary tumor.

In medical history-taking, the patient reported an admission due to abdominal discomfort, jaundice and palpitation two years earlier. The patient was diagnosed with atrial fibrillation, for which amiodarone was prescribed. $\mathrm{He}$ then experienced a spontaneous resolution of his abdominal discomfort and jaundice, with no etiological definition at that time.

In the current admission, the patient presented with a cholestatic syndrome, and physical examination revealed tachycardia, fibroelastic diffuse goiter (approximately $50 \mathrm{~g}$ ), no palpable nodules, a fine tremor of hands, palpebral retraction, bilateral ocular proptosis, periorbital edema, conjunctival hyperemia and chemosis. An investigation revealed the following laboratory test results: thyroid-stimulating hormone (TSH): $0.01 \mathrm{mIU} / \mathrm{L}$ (reference range: $0.35-4.94 \mathrm{mIU} / \mathrm{L}$ ), free T4: $4.53 \mathrm{ng} / \mathrm{dL}$ (reference range: $0.7-1.8 \mathrm{ng} / \mathrm{dL}$ ), TSH receptor antibodies (TRAb): $17.99 \mathrm{U} / \mathrm{L}$ (reference range: $<1.5 \mathrm{U} / \mathrm{L}$ ), and anti-thyroid peroxidase antibodies (anti-TPO): $155.10 \mathrm{U} / \mathrm{mL}$ (reference range: $<15 \mathrm{U} / \mathrm{ml}$ ). A thyroid ultrasonography revealed a diffuse gland enlargement with homogeneous echotexture as well as reactive cervical lymph nodes. Therefore, the patient was
Clin Biomed Res. 2019;39(1):101-103

1 Faculdade de Medicina, Universidade Federal de Pelotas (UFPel). Pelotas, RS, Brasil.

2 Universidade Nilton Lins (UNINILTON). Manaus, AM, Brasil.

3 Programa de Pós-Graduação, Universidade Federal de Pelotas (UFPel). Pelotas, RS, Brasil.

4 Universidade Católica de Pelotas (UCPEL). Pelotas, RS, Brasil.

5 Setor de Endrocrinologia, Universidade Federal de Pelotas (UFPel). Pelotas, RS, Brasil.

6 Departamento de Clínica Médica, Universidade Federal de Pelotas (UFPel). Pelotas, RS, Brasil.

Corresponding author: Rodrigo Piltcher da Silva rodrigopiltcher@gmail.com Faculdade de Medicina, Universidade Federal de Pelotas (UFPel) Avenida Duque de Caxias, 250. 96030-000, Pelotas, RS, Brasil. 
diagnosed with hyperthyroidism due to GD. Cardiac evaluation was performed with an electrocardiogram (ECG), and a transthoracic echocardiogram confirmed high-response atrial fibrillation and mild left atrial dilation.

Amiodarone was suspended due to a possible hepatotoxicity and interference on thyroid function, and beta-blockers were administered. Concomitantly, an extensive investigation was performed in order to rule out primary liver diseases. Abdominal ultrasonography, abdominal computed tomography (CT), magnetic resonance cholangiography (MRC), and duodenoscopy did not reveal any hepatobiliary alterations. The laboratory evaluation showed negative serology for HIV, hepatitis A, B, and C viruses, anti-mitochondrial and anti-smooth muscle antibodies; ceruloplasmin level of $38.7 \mathrm{mg} / \mathrm{dL}$ (reference range: 21-53 mg/dL); non-reactive anti-nuclear antibodies (ANA); ferritin level of $340 \mathrm{mg} / \mathrm{dL}$ (reference range: 20-330 mg/dL); transferrin saturation index of $40 \%$ (reference range: $20-45 \%$ ); alpha-1-antitrypsin level of $158 \mathrm{mg} / \mathrm{dL}$ (reference range: $90-200 \mathrm{mg} / \mathrm{dL}$ ); immunoglobulin $\mathrm{G}(\mathrm{lgG})$ level of $1,645 \mathrm{mg} / \mathrm{dL}$ (reference range: $700-1,600 \mathrm{mg} / \mathrm{dL}$ ); negative direct Coombs test.

Since severe cholestatic syndrome is a rare event in hyperthyroidism, as described by Wang et al. ${ }^{4}$, a percutaneous hepatic biopsy was performed to exclude other etiologies. The biopsy showed congestion of sinusoids, moderate inflammatory infiltrates, steatosis, and fibroblast foci, which constitute a set of nonspecific findings.

During hospitalization, the patient had variable liver test results (Table). At first, there was a reduction in the values after suspension of amiodarone, which suggested its involvement in the etiology of the case. However, that was followed by a new elevation in the results, thus refuting the hypothesis.

Table: Liver function test results during hospitalization.

\begin{tabular}{|c|c|c|c|c|}
\hline & $\begin{array}{c}\text { TB/DB } \\
(\mathrm{mg} / \mathrm{dL})\end{array}$ & $\frac{\text { AST/ALT }}{\text { (U/L) }}$ & $\begin{array}{c}\text { GGT } \\
\text { (U/L) }\end{array}$ & $\begin{array}{l}\text { ALP } \\
\text { (U/L) }\end{array}$ \\
\hline $02 / 07$ & $24.6 / 20$ & $92 / 93$ & 215 & 225 \\
\hline $02 / 11$ & 13.9/11.4 & $74 / 99$ & 195 & 198 \\
\hline $02 / 26$ & $3.5 / 3.4$ & $25 / 31$ & 257 & 167 \\
\hline $03 / 29$ & $11.4 / 10.6$ & $28 / 21$ & 223 & 243 \\
\hline $04 / 12$ & $24 / 22.2$ & $32 / 23$ & 216 & 274 \\
\hline $04 / 18$ & $12.1 / 11.3$ & - & - & - \\
\hline $05 / 02$ & $3.8 / 3.7$ & - & - & 一 \\
\hline $07 / 16$ & $0.83 / 0.57$ & $22 / 10$ & 92 & 191 \\
\hline RR & $<1.2 /<0.3$ & $<37 /<41$ & $<73$ & $<110$ \\
\hline
\end{tabular}

Total bilirubin (TB), direct bilirubin (DB), aspartate aminotransferase (AST), alanine aminotransferase (ALT), gamma-glutamyl transferase (GGT), alkaline phosphatase (ALP), reference range (RR).
Because of the severe evolution of liver disease, the hypothesis that cholestasis was secondary to hyperthyroidism, the impossibility of treatment with tapazole and the presence of ophthalmopathy, the chosen approach was total thyroidectomy. Control of liver function and cholestasis was recovered after the procedure on April 12, 2018, and laboratory results were normal after 30 days, as shown in the Table.

\section{DISCUSSION}

The present study reports the case of a patient who presented with severe cholestatic syndrome secondary to GD. Although a study conducted by Gürlek et al. has demonstrated that the presence of hepatic impairment is found in $60 \%$ of patients with hyperthyroidism ${ }^{5}$, cases of severe cholestasis are rare (around 6.6\%) in the literature ${ }^{4,6}$. Thus, in order to be sure that GD was the etiology of hepatic dysfunction in the current patient, other conditions had to be excluded through complementary laboratory tests, imaging tests and liver biopsy. Moreover, observing whether cholestasis would improve after appropriate treatment of thyrotoxicosis was necessary ${ }^{2}$.

Among the differential diagnoses for jaundice in patients with GD are the thyrotoxic crisis itself, the use of antithyroid drugs (thionamides), autoimmune hepatitis, primary biliary cholangitis (PBC), Gilbert's syndrome, hepatic congestion secondary to heart failure, or thrombosis of the hepatic artery due to atrial fibrillation 6 . In addition, other common causes of hyperbilirubinemia unrelated to this thyroid disorder should be excluded, such as viral hepatitis, alcohol abuse, cholangitis, and other medications ${ }^{7}$.

There is no consensus regarding the mechanism of liver injury due to hyperthyroidism. The most accepted theory is that hypoxia occurs in centrilobular regions due to an increase in oxygen demand without adequate growth of hepatic blood flow ${ }^{6,8}$. Liver biopsy findings are nonspecific, consisting of mild lobular inflammatory infiltrate with neutrophils, eosinophils, and lymphocytes associated with Kupffer cell hyperplasia, as well as intrahepatic cytoplasmic cholestasis ${ }^{8}$.

Regarding treatment, total thyroidectomy was the best option for this patient instead of thionamides and radioactive iodine because of the liver dysfunction and ophthalmopathy. In Brazil, tapazole is the first therapeutic choice for GD. However, in the present case, hepatotoxicity inherent to thionamides limited their use $\mathrm{e}^{9-11}$.

In conclusion, this case report draws attention to an unusual presentation of GD with hepatic dysfunction. Abnormal liver function test results are 
often observed in patients with hyperthyroidism, and clinicians should be aware of this situation. However, this patient presented with severe cholestasis, a rare condition that requires prompt diagnosis, etiological investigation and management. Appropriate diagnosis and treatment of hyperthyroidism was essential for improving the patient's symptoms and liver dysfunction.

\section{Conflicts of Interest}

The authors declare no conflicts of interest.

\section{REFERENCES}

1. Maia AL, Scheffel RS, Meyer ELS, Mazeto GMFS, Carvalho GA, Graf $\mathrm{H}$ et al. Consenso brasileiro para o diagnóstico e tratamento do hipertireoidismo: recomendações do Departamento de Tireoide da Sociedade Brasileira de Endocrinologia e Metabologia. Arq Bras Endocrinol Metab. 2013;57(3):205-32. http:// dx.doi.org/10.1590/S000427302013000300006.

2. Hegazi MO, Ahmed S. Atypical clinical manifestations of graves disease: an analysis in depth. J Thyroid Res. 2012;2012:768019. http:// dx.doi.org/10.1155/2012/768019. PMid:22132347.

3. Neves C, Alves M, Delgado JL, Medina JL. Doença de Graves. Arq Med. 2008;22(4-5):137-46.

4. Wang R, Tan J, Zhang G, Zheng W, Li C. Risk factors of hepatic dysfunction in patients with Graves' hyperthyroidism and the efficacy of 131iodine treatment. Medicine (Baltimore) 2017;96(5):e6035. http://dx.doi. org/10.1097/MD.0000000000006035. PMid:28151911.

5. Gürlek A, Cobankara V, Bayraktar M. Liver tests in hyperthyroidism: effect of antithyroid therapy. J Clin Gastroenterol. 1997;24(3):180-3. http://dx.doi. org/10.1097/00004836-19970400000013. PMid:9179740.

6. Wickramasinghe RDSS, Luke WA, Sebastiampillai BS, Gunathilake MP, Premaratna R. Thyrotoxic crisis presenting with jaundice. BMC Res Notes. 2016;9(1):320. http://dx.doi. org/10.1186/s13104-016-2126-z. PMid:27338936.

7. Chawla M, Bal CS. Four Cases of Coexistent Thyrotoxicosis and Jaundice: Results of Ra-dioiodine Treatment and a Brief Review. Thyroid. 2008;18(3):289-92. http:// dx.doi.org/10.1089/thy.2007.0123. PMid:18225976.
8. Malik R, Hodgson $\mathrm{H}$. The relationship between the thyroid gland and the liver. QJM. 2002;95(9):559-69. http:// dx.doi.org/10.1093/qjmed/95.9.559. PMid:12205333.

9. Yan LD, Thomas D, Schwartz M, Reich J, Steenkamp D. Rescue of graves thyrotoxicosis-induced cholestatic liver disease without antithyroid drugs: a case report. Journal of the Endocrine Society. 2017;1(3):231-6. http:// dx.doi.org/10.1210/js.2016-1065 PMid:29264480.

10. Niculescu DA, Dusceac R, Galoiu SA, Capatina CA, Poiana C. Serial changes of liver function tests before and during methimazole treatment in thyrotoxic patients. Endocr Pract. 2016;22(8):9749. http://dx.doi.org/10.4158/EP161222. OR. PMid:27042749.

11. McCarthy M, McNair ANB, Pinto T. Cholestatic jaundice associated with hyperthy-roidism in the absence of heart failure. CME Gastroenterology. 2001:4:69-71. 